\title{
REVISTARQUIS/10
}

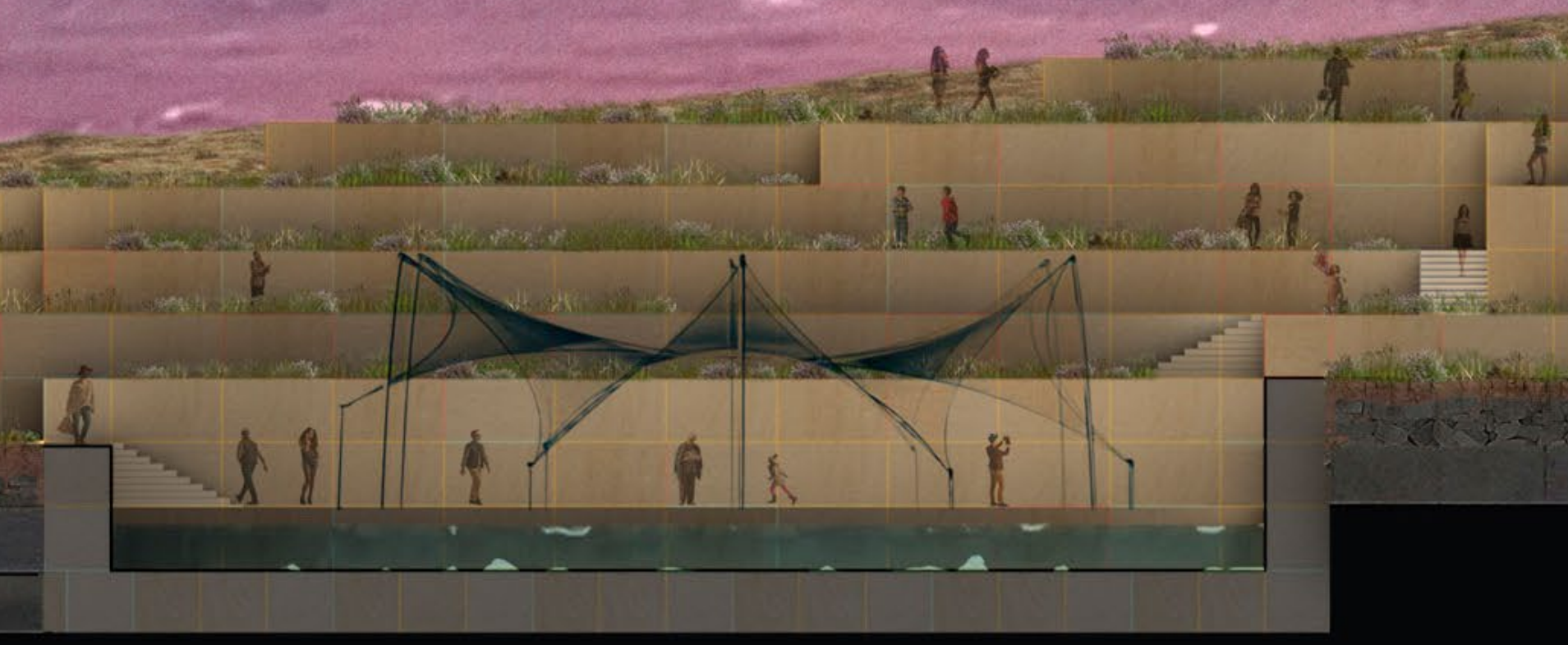


Ciudad y Territorio 


\section{De la urbanización a la intervención urbana estratégica: Instrumentos de planificación intermedia en Costa Rica}

MSc. Roy Allan Jiménez Céspedes, Arquitecto

Invitado nacional

Ministerio de Vivienda y Asentamientos Humanos. Costa Rica

allan.delalto@gmail.com

Recibido: agosto del 2015

Aceptado: noviembre del 2016

Roy Allan Jiménez Céspedes

Arquitecto y urbanista. Especialista en ordenamiento territorial, planificación urbana e instrumentos de gestión del suelo. Ha participado en diferentes foros y programas de formación en nuevos instrumentos de gestión del suelo urbano en países como Brasil, Ecuador, El Salvador, Colombia, Japón y China. Máster en Proyecto Avanzado de Arquitectura y Ciudad con énfasis en Intervenciones Urbanas de la Universidad de Alcalá en Madrid, España, 2016. Licenciado en Arquitectura por la Universidad de Costa Rica.

Ciudady Territorio Ensayo 


\title{
Resumen
}

El presente artículo analiza el contexto y las posibilidades normativas del país para implementar estrategias de planificación de grandes conjuntos urbanos. Este tipo de planificación se ubica entre los planes reguladores locales y la ejecución del proyecto individual. Su aplicación tiene el alcance del conocido pero nunca aplicado "plan maestro". Los actuales formatos de transformación del suelo en Costa Rica impiden un abordaje integral de grandes conjuntos urbanos. La separación práctica de la figura de la urbanización y del condominio ha generado una mejor salida en el mercado inmobiliario del segundo. Grandes áreas de la ciudad han sido intervenidas bajo el formato de condominio horizontal. Esta práctica aceptada e institucionalizada, provoca que la trama urbana existente experimente un proceso de sobrecarga. Al mismo tiempo, el condominio horizontal se considera exento de las cesiones que el desarrollo inmobiliario debe brindar a la ciudad. La renovación urbana, inexplorada pero existente en nuestra normativa, abraza muchas de las posibilidades para la implementación de diferentes procesos de escala intermedia.

Palabras clave: planificación urbana; plan regulador; plan parcial; reajuste de terrenos; renovación urbana.

\begin{abstract}
This paper analyzes the opportunities of Costa Rica to implement planning strategies for large urban sectors. This kind of planning takes place between municipal planning (localgovernment) and specific (urban) projects, in which case, replaces the quite known but difficult to apply "master plan". The current patterns of urban development and real estate in Costa Rica, prevent an integrated approach on large urban sectors. The lack of commercial advantages of the traditional urban development versus the gated community has provoked that large sectors of the city have been intervened as closed environments. The consequences of this very profitable and institutionalized practice are the overload on existing urban areas and the deficit of public facilities, which are necessary for an adequate urban growth. The urban renewal concept, unexplored but present in Costa Rican urban regulations, sets up the ground rules for the approach to large urban areas, also known as partial plans.
\end{abstract}

Keywords: Urban planning; master plan; partial plan; land readjustment; urban renewal. 


\title{
De la urbanización a la intervención urbana estratégica: Instrumentos de planificación intermedia en Costa Rica
}

\author{
Roy Allan Jiménez Céspedes
}

\section{Introducción}

Las técnicas actuales de transformación del suelo existentes en la normativa costarricense dificultan la incidencia en territorios de escala intermedia ${ }^{1}$. Sin embargo, si estudiamos sus características, es posible establecer las bases de una figura que permita intervenir estratégicamente la ciudad.

Para esto, es importante el establecimiento de un sistema de planificación urbana jerarquizado y en cascada. Este sistema debe velar por la coherencia entre las políticas urbanas a nivel nacional, regional y local.

Seguidamente, la intervención de grandes conjuntos precisa de una herramienta técnico legal que haga atractiva la inversión en proyectos de gran escala. Al mismo tiempo, esta herramienta debe promover el crecimiento de la conectividad vial, la definición de amanzanamientos adecuados y usos mixtos del suelo.

En busca de perfilar esta herramienta técnico legal, se analizarán tanto las características de las técnicas de desarrollo inmobiliario existentes en Costa Rica, así como los aspectos de la normativa urbanística vigente que puedan ser rescatados e implementados en proyectos de gran escala.

La renovación urbana, tarea pendiente en el urbanismo nacional, sienta las bases para la creación de una figura innovadora que promueva la intervención de amplios sectores urbanos.

\footnotetext{
$1 \quad$ Se entiende por técnicas de transformación del suelo a aquellos procesos establecidos en la Ley de Planificación Urbana 4240 de 1967 que implican la trasformación de terrenos rústicos a terrenos urbanos, mediante su segregación o bien la construcción de infraestructura urbanística. El artículo 1 de la Ley establece el Fraccionamiento o la Urbanización como los instrumentos para realizar esta transformación.
} 


\section{Ordenamiento territorial y escalas de planificación urbana}

Una vieja máxima de la planificación urbana reza: "Pensar globalmente, actuar localmente". Los instrumentos de planificación como los planes de ordenamiento territorial y los planes urbanísticos, deben en la medida de lo posible, seguir una lógica de planificación en cascada. Es necesario buscar la coherencia entre las políticas y estrategias de desarrollo planteadas por los países, las regiones y los gobiernos locales.

La planificación regional encuentra su auge en de la década de los 80 con el surgimiento del ordenamiento territorial como disciplina incorporada en la acción administrativa de los estados nacionales. Los instrumentos de planificación de escala regional aparecen para definir los lineamientos generales bajo los cuales se construyen los planes urbanísticos locales (Carta Europea de Ordenación del Territorio, 1983). Otro detonante de esta condición lo constituye el auge del hecho metropolitano en el mundo. El crecimiento y la conurbación de diferentes centros urbanos, representa un nuevo reto para el desarrollo. Sólo en América Latina el auge del hecho metropolitano es innegable:

"La expansión urbana ha hecho que muchas grandes ciudades desborden los límites administrativos de sus municipios y terminen absorbiendo físicamente otros núcleos urbanos mediante un proceso de conurbación. El resultado ha sido la aparición de áreas urbanas de grandes dimensiones territoriales, a veces formalizadas en un área metropolitana, integradas por múltiples municipios y con una intensa actividad económica”2.

El surgimiento de las mega ciudades y de las ciudades intermedias queda en evidencia al observar el crecimiento urbano de 1950 a la fecha. "América Latina registra la aparición de 8 mega ciudades con población entre 5 y 10 millones de personas y 55 ciudades en el rango de 1 a 5 millones de personas" 3 . Por parte de Costa Rica, el Gran Área Metropolitana (GAM) figura en este grupo de urbes.

El abordaje de la dinámica regional permite la planificación de los aspectos estructurantes de la ciudad que trascienden las fronteras municipales: la fragilidad ambiental, el transporte público masivo, las redes primarias de servicios básicos, la disposición de desechos sólidos y el concepto general de ciudad.

\footnotetext{
2 Programa de la Naciones Unidas para los Asentamientos Humanos. (2012). Estado de las Ciudades de América Latina y el Caribe 2012. Recife, Brasil: ONU HABITAT. Página 33.

3 Programa de la Naciones Unidas para los Asentamientos Humanos. (2012). Estado de las Ciudades de América Latina y el Caribe 2012. Recife, Brasil: ONU HABITAT. Página 26.
} 
De esta manera, la planificación en cascada incluiría en primer término los lineamientos de desarrollo nacional, en segundo término, los planes regionales de ordenamiento territorial, los planes metropolitanos y, por último, los planes locales municipales.

Adicionalmente, entre los planes urbanos municipales (planes reguladores en el contexto costarricense) y la ejecución del proyecto inmobiliario, existe un nivel intermedio cuya ausencia representa un importante vacío en la definición de la trama urbana de las ciudades. Esta planificación intermedia, ubicada entre la escala del plan regulador y la construcción de proyectos, es la denominada escala parcial o intervenciones urbanas estratégicas.

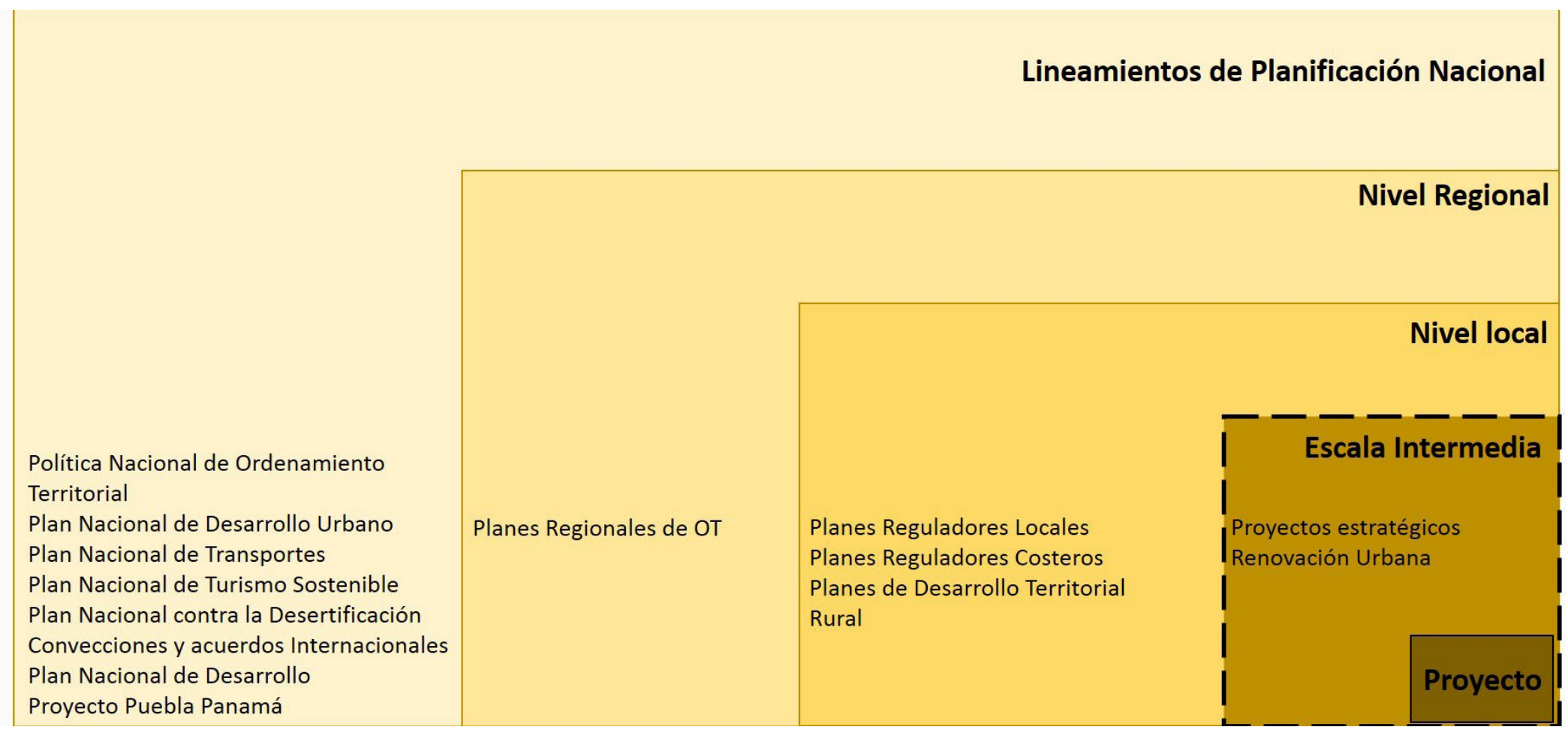

Figura 1. Esquema de planificación en cascada. Nótese el Nivel escala Intermedia. Imagen de elaboración propia.

\section{Pasando del proyecto a la intervención urbana estratégica}

La actividad inmobiliaria es el motor de la transformación de las ciudades, constantemente se tramitan y construyen miles de metros cuadrados de construcción que definen la trama urbana y perfilan nuestras ciudades. La planificación urbanística pretende orientar este desarrollo de la manera más sostenible y adecuada para el bien común, así como fortalecer e incentivar la inversión. Sin embargo, entre la escala local, y el proyecto inmobiliario existen muchas zonas estratégicas de la ciudad que 
requieren un abordaje más detallado. El proyecto inmobiliario nace de diversas lógicas y motivaciones que no precisamente obedecen a la consolidación del "tejido urbano"4.

Dependiendo del caso, el proyecto inmobiliario - de la manera en que actualmente se aprueba en nuestro país- presenta las siguientes limitaciones, cuando de consolidar y completar el tejido urbano se refiere:

\section{El proyecto inmobiliario surge a partir de una geometría de los lotes poco controlable}

El proyecto generalmente se circunscribe a un terreno específico -ya fraccionado o por fraccionar -dependiendo si el predio se encuentra en zona urbana o rural-. Si el terreno se encuentra en un cuadrante urbano, queda en manos del desarrollador privado lograr la unificación de los predios circundantes con el objetivo de emprender un proyecto de escala intermedia. Si el predio es rural y lo que se busca es urbanizarlo o fraccionarlo, la forma del lote generalmente obedecerá a los procesos agrícolas previos, inhibiendo la adecuada integración del proyecto a la ciudad y la construcción de una adecuada trama vial. En la figura 2 se observa como la geometría resultante de los lotes no siempre obedece a un tejido urbano adecuado. Los proyectos inmobiliarios terminan "adaptándose" a geometrías irregulares. Cada propietario de terreno desarrolla su predio sin mayor integración o mejoras a las condiciones generales de funcionalidad. Algunas consecuencias de esta práctica son: La fragmentación del espacio público, ausencia de áreas verdes, estrangulamiento de cauces de ríos y quebradas, pérdida de cobertura vegetal, una inadecuada red vial y proyectos con un único uso del suelo, sin mixtura de actividades. Aunque el proyecto inmobiliario se termine con éxito, su entorno pierde en competitividad y calidad espacial. Este proceso es denominado "desarrollo predio a predio".

\footnotetext{
4 Nota del autor: Por "tejido urbano" se entiende a los componentes básicos que estructuran la ciudad de una manera funcional: la trama vial, incluyendo los diferentes tipos de movilidad, el amanzanamiento, asociado a la configuración de las cuadras y la provisión de espacios públicos. Y los usos del suelo, relacionado con los aprovechamientos, los parámetros constructivos y los tratamientos urbanos específicos. Si el tejido urbano se consolida, contará con un desarrollo claro de los tres componentes antes mencionados.
} 

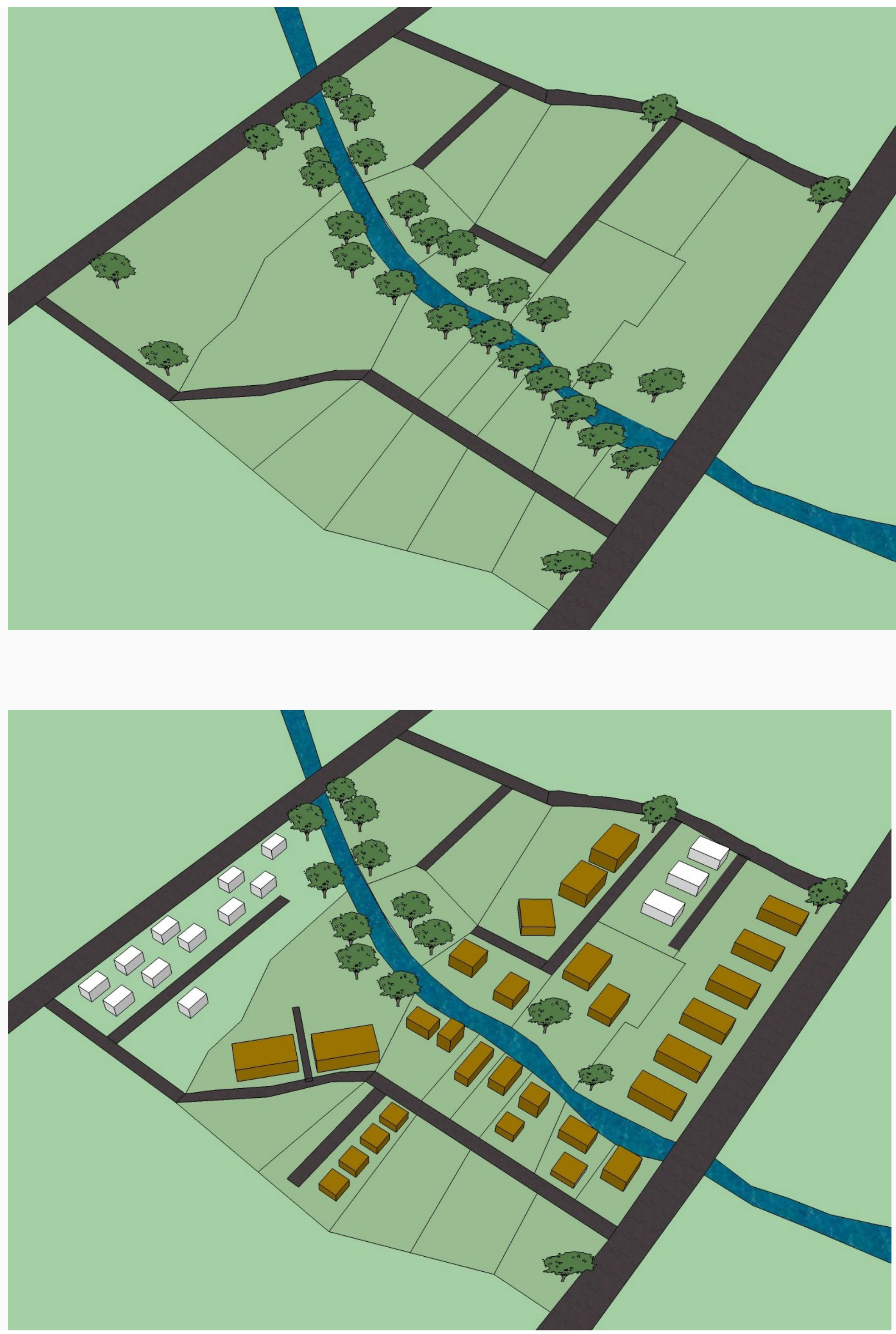

Figura 2. Desarrollo inmobiliario predio a predio. Imágenes de elaboración propia. 
2. El proyecto inmobiliario tiene un impacto reducido o negativo en el espacio público

Al desarrollarse los proyectos inmobiliarios sin una visión general del sector urbano al que pertenecen, las cesiones de espacio público terminarán ubicándose de manera desarticulada en la ciudad, o peor aún, (bajo el entendimiento actual de la figura del condominio en el contexto costarricense), ni siquiera se cederán espacios públicos para la colectividad.

Aunque la figura del condominio horizontal puede abarcar grandes extensiones (Figura 3) este tipo de comunidades cerradas tienen una serie de impactos negativos a saber: 1 . No aportan vías públicas, lo que reduce la redundancia vial y la conectividad general de la ciudad. 2. Se limitan a la geometría del terreno existente, lo que impide mejorar el tejido urbano, 3. No aportan áreas públicas a la colectividad, 4. Las tapias perimetrales generan un fuerte impacto al paisaje, 5 . Carecen de mixtura en el uso del suelo provocando que los habitantes tengan que desplazarse en busca de servicios. 6 . acentúan procesos de segregación residencial.
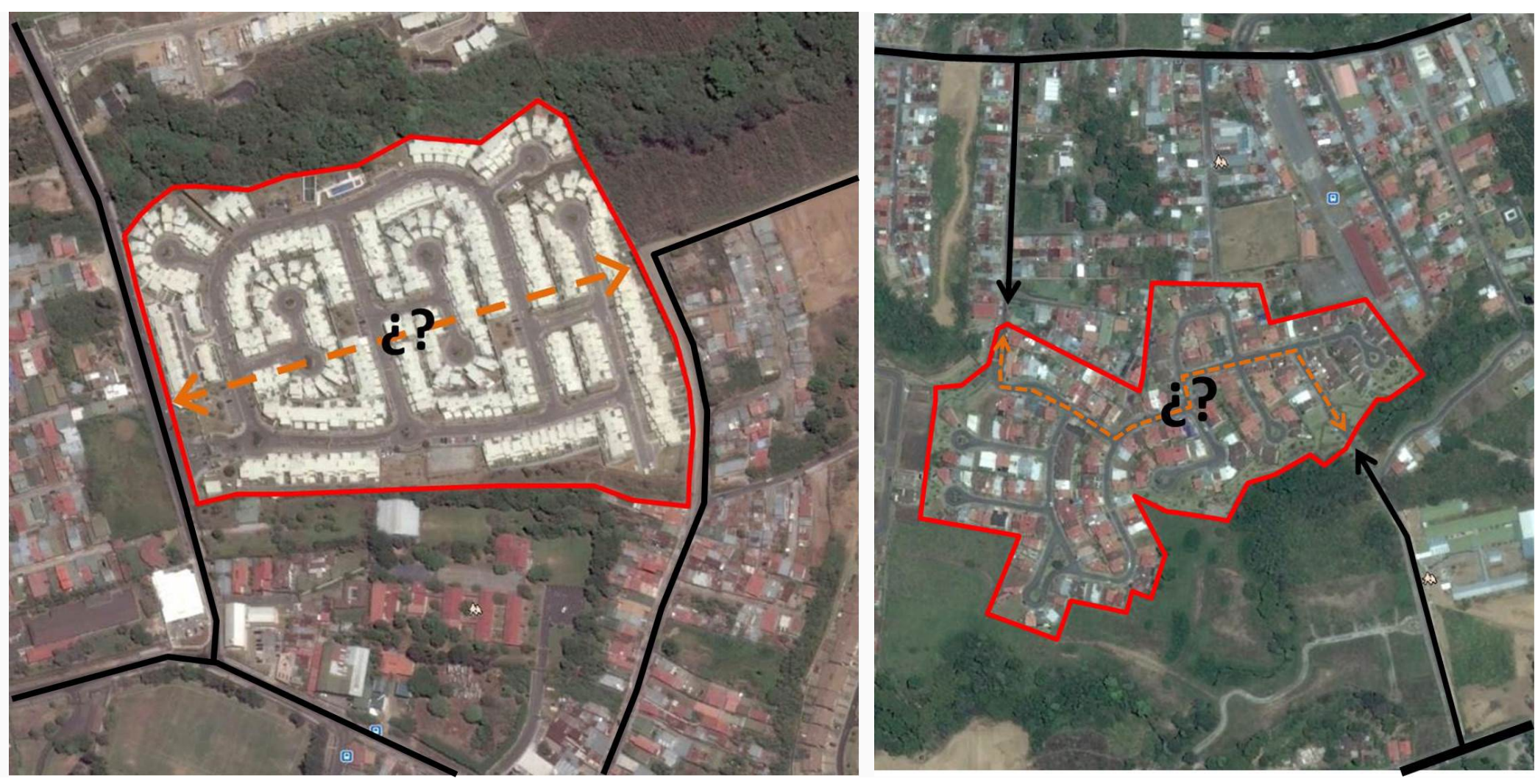

Figura 3. Imagen de elaboración propia con fotografías tomadas de Google Earth.com. 
3. El uso del suelo no obedece a la mejor lógica financiera del proyecto inmobiliario

Aunque en nuestro país la zonificación incluye una tipificación de las posibles actividades a realizar en las diferentes zonas, esta caracterización de usos no es realizada desde el punto de vista de las rentas que se puedan generar. Por lo tanto, al intervenir terrenos aislados, los proyectos pierden la oportunidad de integrarse a otros usos ya planificados o, por el contrario, se corre el riesgo de sobrecargar una zona con un uso específico. Esto puede ir en detrimento de actividades comerciales o bien de los intereses comunes - como, por ejemplo, barrios históricos que han sido tomados por un único uso que impide su conservación; o bien, grandes sectores de la ciudad solo con usos residenciales, generando comunidades dormitorio-.

La planificación a escala intermedia, permite definir perímetros de actuación donde se pretenda realizar una intervención a escala urbana. Los aspectos básicos de la trama urbana deben quedar resueltos a priori, y los proyectos que se ejecuten tendrán implícitas estas mejoras generales. Dependiendo de los países, la escala de estas intervenciones puede variar, rondando en el caso de América Latina, las 10 hectáreas 5. Este tipo de intervención es vista como una intervención única, con diferentes etapas de implementación, las cuales incluyen el reajuste de las geometrías tanto de lotes como de calles y espacio públicos.

Algunas ventajas de la planificación a escala parcial para la ciudad son las siguientes:

- La geometría de los terrenos puede ser adaptada para mejorar la trama vial y garantizar su mejor aprovechamiento.

- El espacio público gana en jerarquía y calidad espacial.

- Los usos del suelo y aprovechamiento pueden adaptarse a la mejor rentabilidad financiera de los proyectos, a través de usos mixtos, incentivos y parámetros constructivos determinados específicamente para los proyectos.

- Al ser una intervención de escala superior, la tramitación se simplifica y se hace más expedita conforme se avanza en la ejecución de los proyectos.

5 Los casos más estudiados de intervenciones urbanas a escala intermedia en América Latina se encuentran en Colombia y Brasil, en la forma de "Planes Parciales" o bien "Operaciones Urbanas Consorciadas". Por otro lado, otras herramientas de planificación intermedia similares en el mundo son las "Zonas de Planificación Concertada" en Francia, el KUKAKUSEIRI -- en Japón o las Zonas Económicas Especiales -ZEE- en China. 
Los planes urbanos de las ciudades deben definir los parámetros específicos de ubicación, extensión y situaciones a ser abordadas en estos sectores que requieran un abordaje diferenciado. Estos parámetros no solo deben ser de carácter físico espacial, sino que deben incluir las reglas del juego para el reajuste de las geometrías prediales, la negociación con los dueños de la tierra y el reparto de las cargas y beneficios generados de las operaciones.

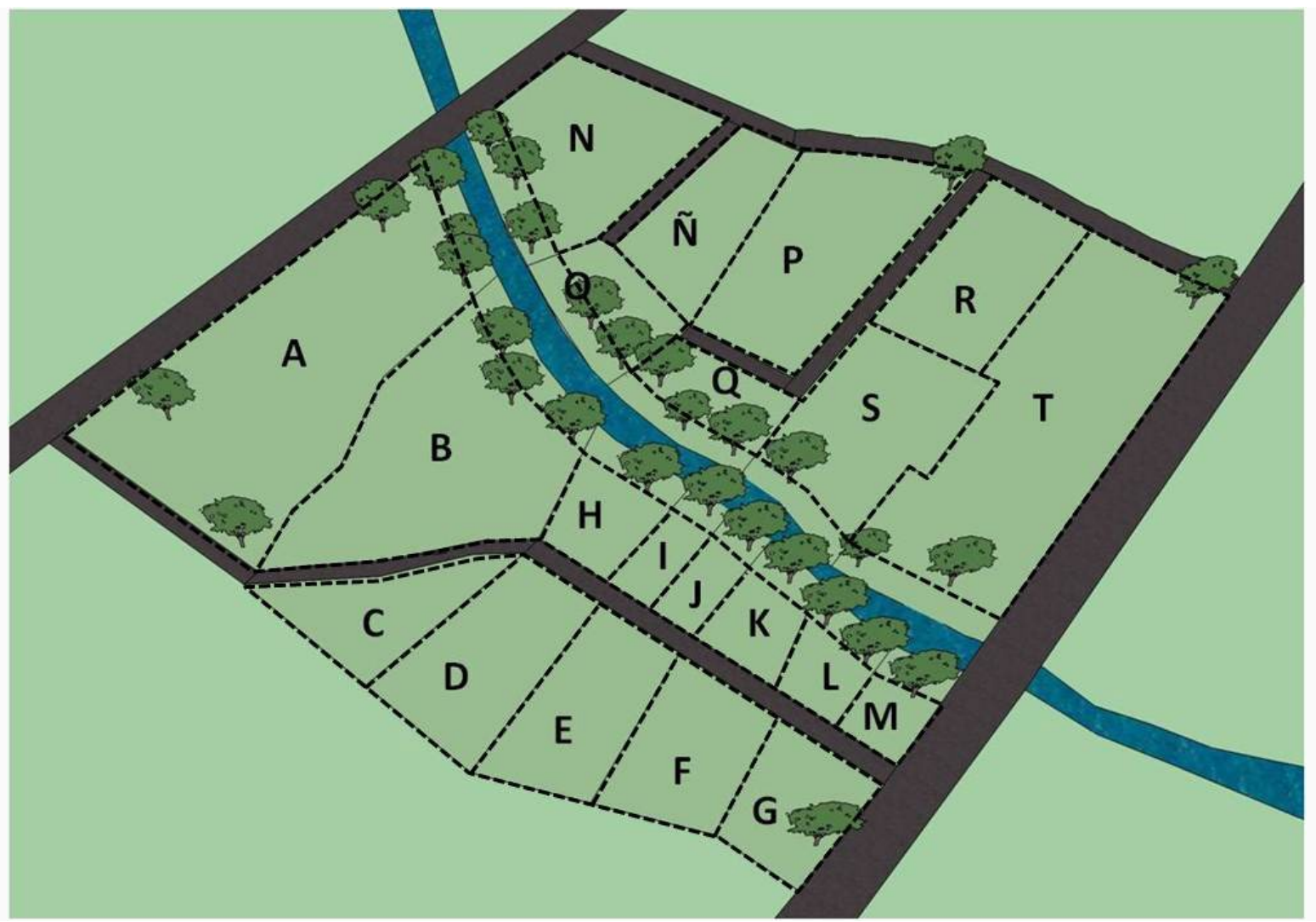

Figura 4. Esquema inicial antes del reajuste, El perímetro contiene a diversos dueños de terrenos los cuales poseen geometrías irregulares probablemente producto de su uso agrícola previo. Imagen Roy Allan Jiménez Céspedes

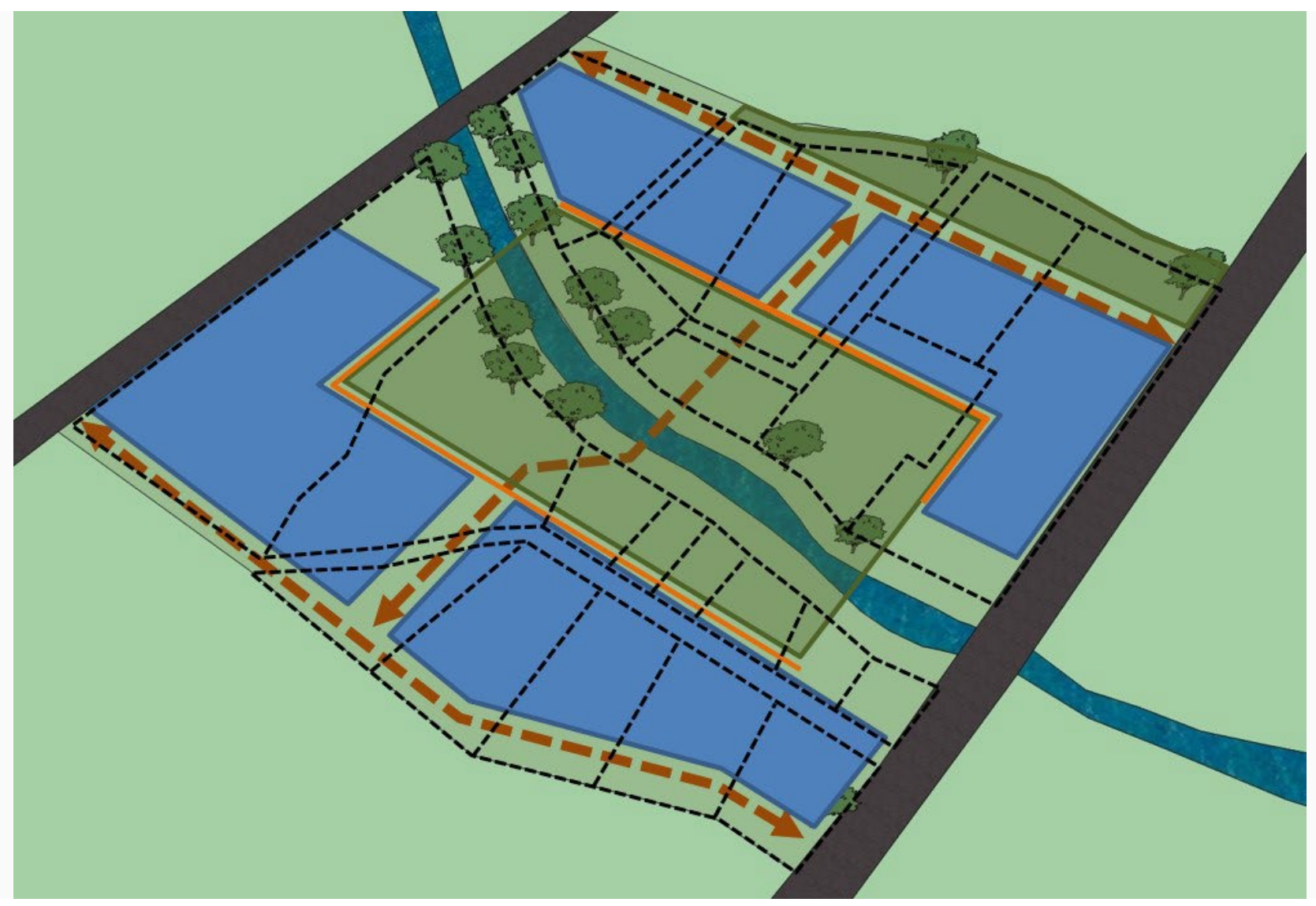

Figura 5. Al incorporarlos en el proceso de escala intermedia, mediante el reajuste se borran los límites prediales y se realiza el plan general que define la trama vial y la utilización del suelo. Imagen Roy Allan Jiménez Céspedes 


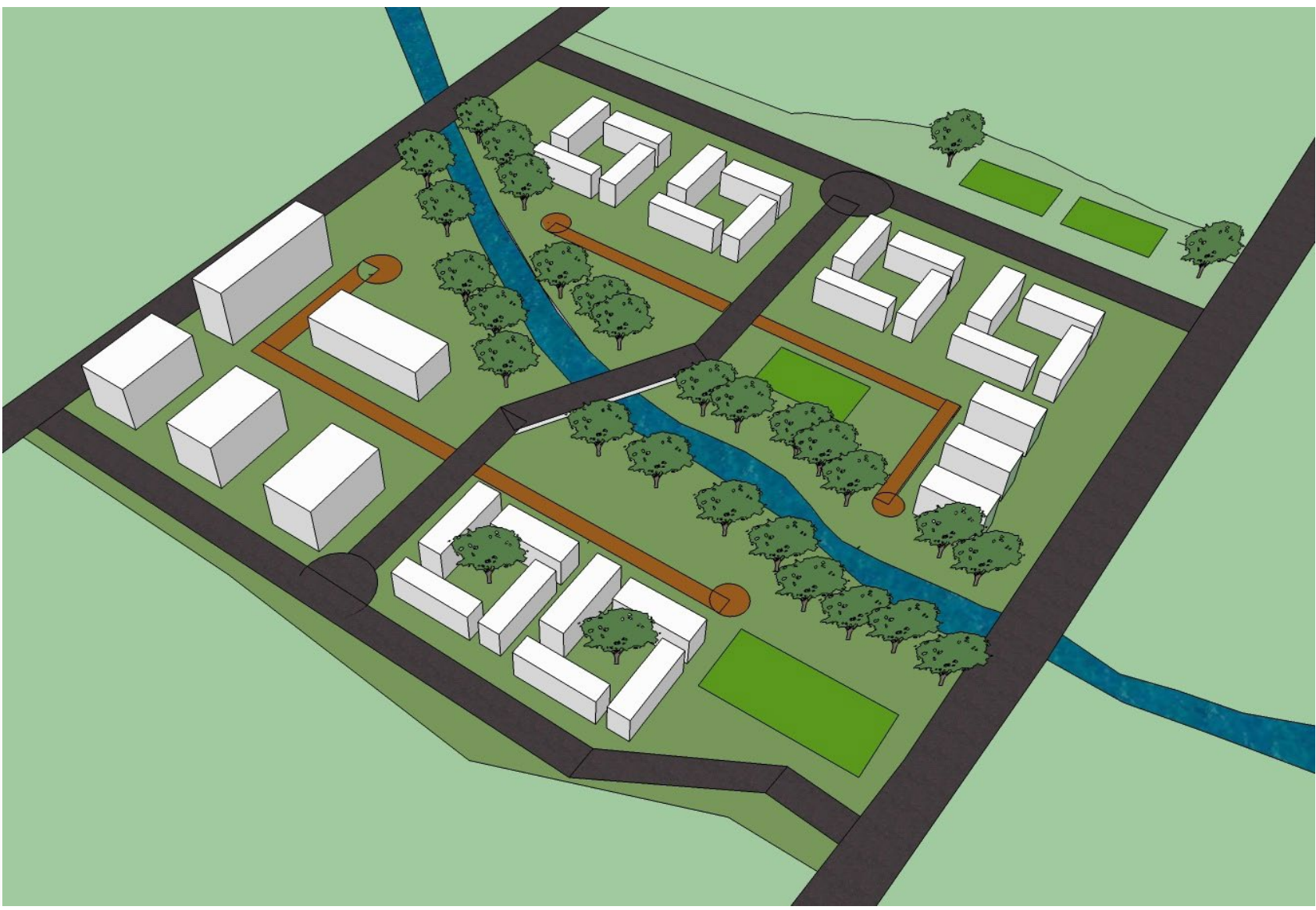

Figura 6. Al final de la operación, el área total muestra una trama vial diferente y las rentas de la operación se reparten proporcionalmente entre los dueños de terreno. Imagen Roy Allan Jiménez Céspedes.

Bajola figura de la escala intermedia, los planteamientos urbanísticos deben considerar el reajuste de las geometrías prediales -de ser necesario-, la adecuada consolidación de la trama vial y el establecimiento de un sistema de usos del suelo que garantice el éxito financiero de la intervención.

\section{El alcance del proyecto inmobiliario tradicional y la construcción de ciudad}

En Costa Rica, por debajo del nivel de planificación local, encontramos las herramientas para el desarrollo de proyectos, ya sean estos mediante la construcción de edificaciones puntuales, a través del fraccionamiento en zonas previamente urbanizadas (conocido como fraccionamiento frente a calle pública) o bien mediante la urbanización de terrenos en verde.

En todos estos casos, la construcción de proyectos encuentra sus parámetros constructivos en los planes reguladores -escala local-o ante la ausencia de estos, en los reglamentos nacionales emitidos por el Instituto Nacional de Vivienda y Urbanismo ${ }^{6}$.

$6 \quad$ Ante la ausencia de planes reguladores, el transitorio II de la Ley de Planificación Urbana otorga al Instituto Nacional de Vivienda y Urbanismo (INVU), la competencia residual de generar la normativa urbanística en los territorios sin regulaciones locales: "El Instituto dictará las normas de desarrollo relativas a las materias a que se refiere el artículo 21 de esta Ley. Podrá además, confeccionar los planes reguladores y delimitar los distritos urbanos y demás áreas sujetas a control urbanístico, en tanto las municipalidades no hubieren promulgado en la respectiva materia, o parte de ella, sus propias disposiciones locales con ajuste a esta ley" (Ley 5900 1976). Esta competencia ha sido reiterada en el fallo 4205 de 1996, de la Sala Constitucional. 
Como hablamos de intervenciones a escala intermedia, en el siguiente cuadro se analiza el alcance de las herramientas actuales para la generación de proyectos, versus los objetivos de transformación urbana que se persiguen en los proyectos urbanos estratégicos, se analizan los dos tipo de intervención que pueden abarcar más área según la dinámica inmobiliaria y la normativa urbanística vigente en el país:

Cuadro 1. Posibles herramientas de planificación intermedia Alcance de las herramientas actuales para el abordaje de grandes conjuntos

\begin{tabular}{|c|c|c|c|}
\hline & $\begin{array}{c}\text { Figura del Condominio Horizontal } \\
\text { vertical o mixto* }\end{array}$ & $\begin{array}{l}\text { Urbanización o conjunto } \\
\text { residencial }\end{array}$ & $\begin{array}{l}\text { Intervención Urbana estratégica } \\
\text { de escala intermedia (propuesta) }\end{array}$ \\
\hline ט. & $\begin{array}{l}\text { Modalidad donde cada condómino } \\
\text { es propietario exclusivo de un terreno } \\
\text { propio y de la edificación construida } \\
\text { sobre él y además es copropietario de } \\
\text { las áreas comunes. }\end{array}$ & $\begin{array}{l}\text { Fraccionamiento y habilitación de un } \\
\text { terreno, mediante apertura de calles y } \\
\text { provisión de servicios básicos. }\end{array}$ & $\begin{array}{l}\text { Intervención específica en zonas } \\
\text { consideradas de carácter estratégico } \\
\text { para fines urbanísticos. Incluye la } \\
\text { construcción de infraestructuras para } \\
\text { completar la trama urbana existente y } \\
\text { generación actividades residenciales, } \\
\text { productivas y de servicios. }\end{array}$ \\
\hline$\frac{\substack{\frac{1}{0} \\
\frac{0}{0}}}{0}$ & $\begin{array}{c}\text { Segregación de lotes para la venta } \\
\text { en el contexto de la seguridad } \\
\text { y comodidad del desarrollo en } \\
\text { condominio. No tiene mayores } \\
\text { restricciones de ubicación, según } \\
\text { zonificación del plan regulador y } \\
\text { acceso a calle pública. Hasta la } \\
\text { figura del parcelamiento agrícola y } \\
\text { forestal se ha utilizado para aplicar la } \\
\text { modalidad del condominio residencial } \\
\text { de manera irregular. }\end{array}$ & $\begin{array}{l}\text { Habilitación de nuevos sectores } \\
\text { urbanos, articulados a la ciudad y } \\
\text { con adecuada provisión de servicios. } \\
\text { No tiene mayores restricciones de } \\
\text { ubicación, según zonificación del plan } \\
\text { regulador y acceso a calle pública. }\end{array}$ & $\begin{array}{c}\text { Abordaje a gran escala de una } \\
\text { problemática urbana, ya sea para la } \\
\text { transformación de suelo rural a suelo } \\
\text { urbano o bien, la renovación de áreas } \\
\text { previamente urbanizadas. } \\
\text { Su ubicación debe ser estratégica } \\
\text { y debe ser determinada por la } \\
\text { planificación local. Normalmente se } \\
\text { asocia a zonas centrales urbanas } \\
\text { deterioradas y zonas identificadas } \\
\text { como de expansión urbana. }\end{array}$ \\
\hline $\begin{array}{l}\frac{\pi}{\pi} \\
\text { ల్ } \\
\text { 山 }\end{array}$ & $\begin{array}{c}\text { No tiene límite de aplicación, el } \\
\text { límite lo constituye el terreno a ser } \\
\text { intervenido. La figura del "condominio } \\
\text { de condominios" facilita que se } \\
\text { desarrollen grandes extensiones de } \\
\text { terreno. }\end{array}$ & $\begin{array}{c}\text { No tiene límite de aplicación, el } \\
\text { limite lo constituye el terreno a ser } \\
\text { intervenido }\end{array}$ & $\begin{array}{l}\text { No tiene límite, sin embargo su } \\
\text { alcance probablemente abarcará } \\
\text { más de un terreno colindante, lo que } \\
\text { implicará su unificación o reajuste } \\
\text { geométrico, incluyendo calles y } \\
\text { espacios públicos }{ }^{\star \star} \text {. En algunos países } \\
\text { se establece la medida mínima de } 10 \\
\text { hectáreas. }\end{array}$ \\
\hline 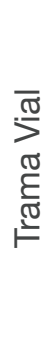 & $\begin{array}{c}\text { El condominio horizontal, por ser una } \\
\text { intervención cuyo resultado físico es } \\
\text { propiedad privada, no genera vialidad } \\
\text { pública que pueda ayudar a completar } \\
\text { la trama urbana. Esto genera que las } \\
\text { vías ya existentes se saturen, como } \\
\text { parte de las consecuencias del efecto } \\
\text { burbuja }\end{array}$ & $\begin{array}{c}\text { La urbanización debe integrarse a la } \\
\text { trama urbana circundante, por lo que } \\
\text { aporta vías alternas y redundancia vial } \\
\text { a la ciudad. }\end{array}$ & $\begin{array}{c}\text { El plan de escala intermedia } \\
\text { debe integrarse a la trama urbana } \\
\text { circundante, por lo que aporta vías } \\
\text { alternas y redundancia vial a la ciudad. }\end{array}$ \\
\hline 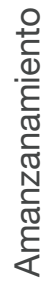 & $\begin{array}{l}\text { Al no sujetarse las vías internas } \\
\text { del condominio a la trama vial } \\
\text { circundante, el amanzanamiento } \\
\text { resultante tiende a ser discordante } \\
\text { con el entorno y geométricamente } \\
\text { complejo. (Espina de pescado) }\end{array}$ & $\begin{array}{l}\text { Al solicitarse que la trama urbana } \\
\text { se integre al contexto, hay más } \\
\text { posibilidad de control y definición de } \\
\text { cuadras o retículas urbanas. }\end{array}$ & $\begin{array}{c}\text { Al ser uno de los objetivos que la } \\
\text { trama urbana se integre al contexto, se } \\
\text { controla y definen cuadras o retículas } \\
\text { urbanas. }\end{array}$ \\
\hline $\begin{array}{l}\frac{0}{0} \\
\frac{1}{D} \\
\frac{D}{0} \\
0 \\
0 \\
\stackrel{0}{D}\end{array}$ & $\begin{array}{l}\text { Determinados por la zonificación } \\
\text { del plan regulador. Normalmente } \\
\text { los condominios horizontales se } \\
\text { dividen en usos residenciales o bien } \\
\text { comerciales. Se generan grandes } \\
\text { proyectos "mono funcionales". Se } \\
\text { pueden encontrar casos de usos } \\
\text { mixtos que aportan mayor actividad a } \\
\text { la ciudad en condominios verticales en } \\
\text { zonas céntricas de la ciudad. }\end{array}$ & $\begin{array}{l}\text { Al solicitarse que la trama urbana } \\
\text { se integre al contexto, hay más } \\
\text { posibilidad de control y definición de } \\
\text { cuadras o retículas urbanas. }\end{array}$ & $\begin{array}{c}\text { Al ser uno de los objetivos que la } \\
\text { trama urbana se integre al contexto, se } \\
\text { controla y definen cuadras o retículas } \\
\text { urbanas. }\end{array}$ \\
\hline
\end{tabular}




\begin{tabular}{|c|c|c|c|}
\hline & $\begin{array}{c}\text { Figura del Condominio Horizontal, } \\
\text { vertical o mixto* }\end{array}$ & Urbanización o conjunto residencial & $\begin{array}{l}\text { Intervención Urbana estratégica de } \\
\text { escala intermedia (propuesta) }\end{array}$ \\
\hline 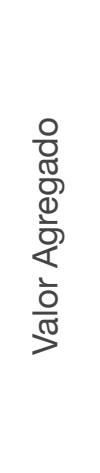 & $\begin{array}{l}\text { El valor agregado de la figura del } \\
\text { condominio radica en la seguridad } \\
\text { y control que se da a lo interno } \\
\text { del proyecto, el cual tiene normas } \\
\text { específicas de convivencia y deberes } \\
\text { y derechos de mantenimiento. Existe } \\
\text { una noción de Status y exclusividad } \\
\text { asociada. Otro aspecto que lo hace } \\
\text { muy atractivo al inversionista, es el } \\
\text { proceso de tramitación único ante el } \\
\text { INVU. }\end{array}$ & $\begin{array}{l}\text { El valor de la urbanización está dirigido } \\
\text { a la colectividad, que recibe más } \\
\text { espacios públicos y conectividades } \\
\text { viales, sin embargo el carácter público } \\
\text { de la herramienta y la tramitación } \\
\text { asociada le resta competitividad frente } \\
\text { al condominio. Son necesarios dos } \\
\text { pasos para generar una urbanización } \\
\text { y luego someter al régimen de } \\
\text { propiedad en condominio la totalidad } \\
\text { o alguna de sus partes. }\end{array}$ & $\begin{array}{c}\text { El valor agregado de estas } \\
\text { intervenciones se da en tres escalas: A } \\
\text { nivel ciudad, se logra un mejoramiento } \\
\text { de la trama urbana y el funcionamiento } \\
\text { de un sector específico. A nivel de los } \\
\text { futuros habitantes, quienes encuentran } \\
\text { el valor agregado del régimen de } \\
\text { propiedad en condominio. A nivel del } \\
\text { inversionista, que ve optimizada la } \\
\text { rentabilidad y el aprovechamiento de } \\
\text { los terrenos a ser intervenidos. }\end{array}$ \\
\hline 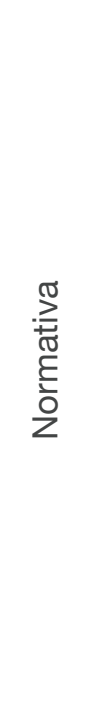 & $\begin{array}{c}\text { Ley Reguladora de la Propiedad } \\
\text { en Condominio, Reglamento de } \\
\text { Condominios, Reglamento para el } \\
\text { Control Nacional de Fraccionamientos } \\
\text { y Urbanizaciones }\end{array}$ & $\begin{array}{l}\text { Ley de Planificación Urbana } \\
\text { Reglamento para el Control } \\
\text { Nacional de Fraccionamientos y } \\
\text { Urbanizaciones. }\end{array}$ & $\begin{array}{l}\text { Actualmente la figura normativa que } \\
\text { permitiría una intervención similar } \\
\text { aunque no con todo el alcance sería } \\
\text { una combinación de las dos anteriores } \\
\text { "Urbanización de Condominios", } \\
\text { sin embargo esta figura pierde } \\
\text { competitividad por requerir dos pasos } \\
\text { de tramitación para su constitución: } \\
\text { 1.Urbanización de lotes (construcción } \\
\text { de infraestructura con cesiones } \\
\text { públicas), 2.Construcción de edificios } \\
\text { y constitución de condominios, el } \\
\text { cual debe prever las áreas comunes } \\
\text { para el condominio. Entre una etapa } \\
\text { y la otra se encuentra la recepción } \\
\text { de la urbanización por parte de la } \\
\text { municipalidad. }\end{array}$ \\
\hline 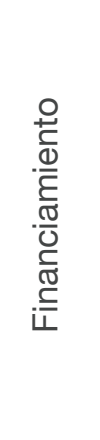 & $\begin{array}{l}\text { La construcción de condominios } \\
\text { horizontales ha tomado mucho auge } \\
\text { en los últimos } 20 \text { años por su fácil } \\
\text { salida en ventas. Bancos y entidades } \\
\text { financieras invierten constantemente } \\
\text { en la construcción de condominios } \\
\text { horizontales. }\end{array}$ & $\begin{array}{l}\text { La urbanización ha sido relegada a un } \\
\text { segundo plano por parte del sector } \\
\text { inmobiliario, centrándose actualmente } \\
\text { su uso para la generación de } \\
\text { proyectos de vivienda social. }\end{array}$ & $\begin{array}{l}\text { La incertidumbre jurídica de la figura y } \\
\text { sus complejos pasos de constitución } \\
\text { hace que esta opción no sea } \\
\text { reconocida por el sector inmobiliario. } \\
\text { Actualmente el gobierno impulsa la } \\
\text { construcción de proyectos piloto } \\
\text { que sigan esta modalidad, con el } \\
\text { fin de demostrar su efectividad y su } \\
\text { necesidad de inclusión en la normativa } \\
\text { urbanística. }\end{array}$ \\
\hline 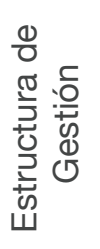 & $\begin{array}{l}\text { Desde el Sector Privado con el estado } \\
\text { como regulador. }\end{array}$ & $\begin{array}{l}\text { Desde el Sector Privado con el estado } \\
\text { como regulador. }\end{array}$ & $\begin{array}{l}\text { Operaciones publico privadas } \\
\text { Operaciones urbanas consorciadas } \\
\text { Sociedades de Economía Mixta }\end{array}$ \\
\hline
\end{tabular}

*Aunque en este artículo y para efectos de esta tabla se considera el condominio horizontal vertical o mixto, como una modalidad de proyecto, el autor aclara que este hecho se consigna de esta manera por la práctica inmobiliaria actual costarricense. Sin embargo, el autor no considera que el condominio constituya un tipo de proyecto o de técnica de transformación del suelo, sino más bien una forma legal de tenencia. Por lo tanto los condominios son en su esencia urbanizaciones o fraccionamientos los cuales deberían estar sujetos a las normas de la Ley de Planificación Urbana incluidas las cesiones de ley. La Procuraduría General de la Republica se ha pronunciado haciendo ver que el condominio es un régimen de propiedad jurídica y no una forma de construcción o transformación del suelo:

"La propiedad en condominio no alude a un tipo de uso del terreno en particular. Es común que se denomine a los edificios de apartamentos como condominios. Y lo cierto es que ese tipo de edificación suele estar sometida a ese régimen jurídico de propiedad, pero puede no estarlo cuando, por ejemplo, pertenece a un solo propietario. De allí que es un error identificar una cosa con la otra. El concepto de condominio hace referencia a un régimen jurídico de propiedad a que pueden ser sometidos los bienes inmuebles, no a un uso de dichos bienes (vivienda por ejemplo) o a un tipo de construcción (un edificio de apartamentos, por ejemplo) (C-290-2006).

**Para mayor información, ver artículo Urbanismo e Instrumentos de Gestión del Suelo en Costa Rica. Revista Habitar del Colegio de Arquitectos, número 86, año 2015. Página 48.

***Se denomina efecto burbuja a la aparición de comunidades cerradas que no aportan redundancia vial ni espacio público,

saturando las vías existentes y generando segregación residencial. 
Como se aprecia en el cuadro, aunque la figura del condominio y la figura de la urbanización pueden llegar a alcanzar grandes extensiones de terreno -incluso de "escala intermedia"-, sus características básicas se limitan a un predio previamente constituido, sin control de la geometría del mismo en función del entorno urbano. En otras palabras, se carece de una verdadera "facultad remodeladora". Por otra parte, ambas figuras muestran tanto aspectos positivos como negativos cuando hablamos de intervenciones de gran escala. Mientras el condominio de gran extensión no logra resolver los aspectos inconclusos de la trama urbana, la urbanización tradicional no garantiza un producto con valores agregados como la privacidad, la facilidad de tramitación, la concertación de los usos del suelo y los aprovechamientos en beneficio financiero del proyecto.

Dicho esto, para lograr la intervención de sectores amplios de la ciudad bajo un modelo que genere tanto beneficios urbanos como financieros, es necesario explorar una estructura de gestión de proyectos de gran escala que incluya: 1 . Un componente previo de planificación urbana -definido de manera consorciada entre el gobierno local y el sector privado-, que contenga los parámetros, metodologías e instrumentos legales para el reajuste de las geometrías prediales y un sistema de incentivos a la inversión; 2. Un proceso de transformación del suelo con los resultados de la urbanización; 3. Un producto de venta al mercado que incluya las bondades del régimen de propiedad en condominio. Todo esto debe conjugarse en un proceso de tramitación único, simplificado y con alto grado de seguridad jurídica.

La figura más cercana a estas características la constituye un híbrido entre la urbanización de un amplio sector urbano - ya sea uno o varios lotes - y la generación de diferentes unidades de actuación o etapas, las cuales puedan albergar diferentes usos mixtos bajo la figura de propiedad condominal. En resumen, se habla de una "urbanización de condominios". Sin embargo, a nivel de trámites y permisos, esta figura al constituir dos procesos, no es atractiva como posibilidad de inversión. Según la normativa, es necesario que las obras de urbanización -calles y áreas públicas- se encuentren terminadas y recibidas por la autoridad municipal antes del inicio de la construcción de las obras a ser sometidas al régimen de propiedad en condominio. Este hecho provoca que los tiempos y la tramitación constituyan el principal escollo. Sin embargo, una figura de este tipo permitiría intervenir grandes extensiones de terreno garantizando su correcta integración al tejido urbano existente, ya sea en un solo terreno de gran tamaño, o bien mediante el reajuste de varios predios. Al mismo tiempo, constituiría un producto de venta atractivo que rentabilice las inversiones. 
En relación a la capacidad remodeladora necesaria para la correcta ejecución de los proyectos de escala intermedia, la normativa costarricense deposita esta competencia en manos de las municipalidades en el marco de los programas de renovación urbana:

Artículo 53: En programa de renovación urbana, la facultad remodeladora permite a la municipalidad abrir y cerrar calles, así como rectificar su trazado.

La municipalidad o el instituto gestionarán con los propietarios de los inmuebles sujetos a remodelación, lo correspondiente a redistribución de lotes, para arreglar por convenio el modo de reubicarles dentro de la misma zona, trasladarles a otra y efectuar compensaciones en dinero o en especie. ${ }^{7}$

Claramente este artículo de la Ley de Planificación Urbana hace mención a la técnica del reajuste de terrenos ${ }^{8}$, utilizada en diversos países del mundo para el desarrollo de proyectos de escala intermedia. Adicionalmente, la Ley de Planificación Urbana solicita un cuarto elemento necesario para la concreción de este tipo de proyectos: Un modelo de reparto de cargas y beneficios que permita distribuir de manera equitativa los costos y rentas generadas por los proyectos urbanos, proporcionalmente al aporte efectuado por los participantes de la operación.

\section{Esquema de reajuste para la Renovación Urbana y el Desarrollo de Apartamentos}

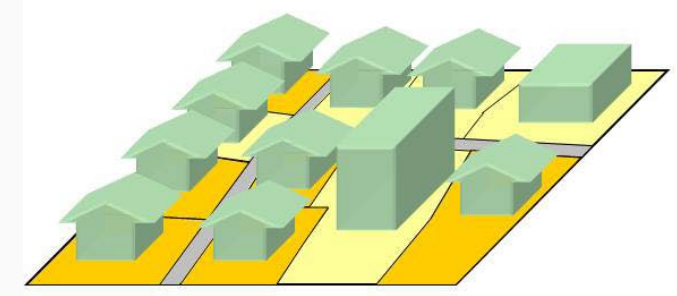

Antes
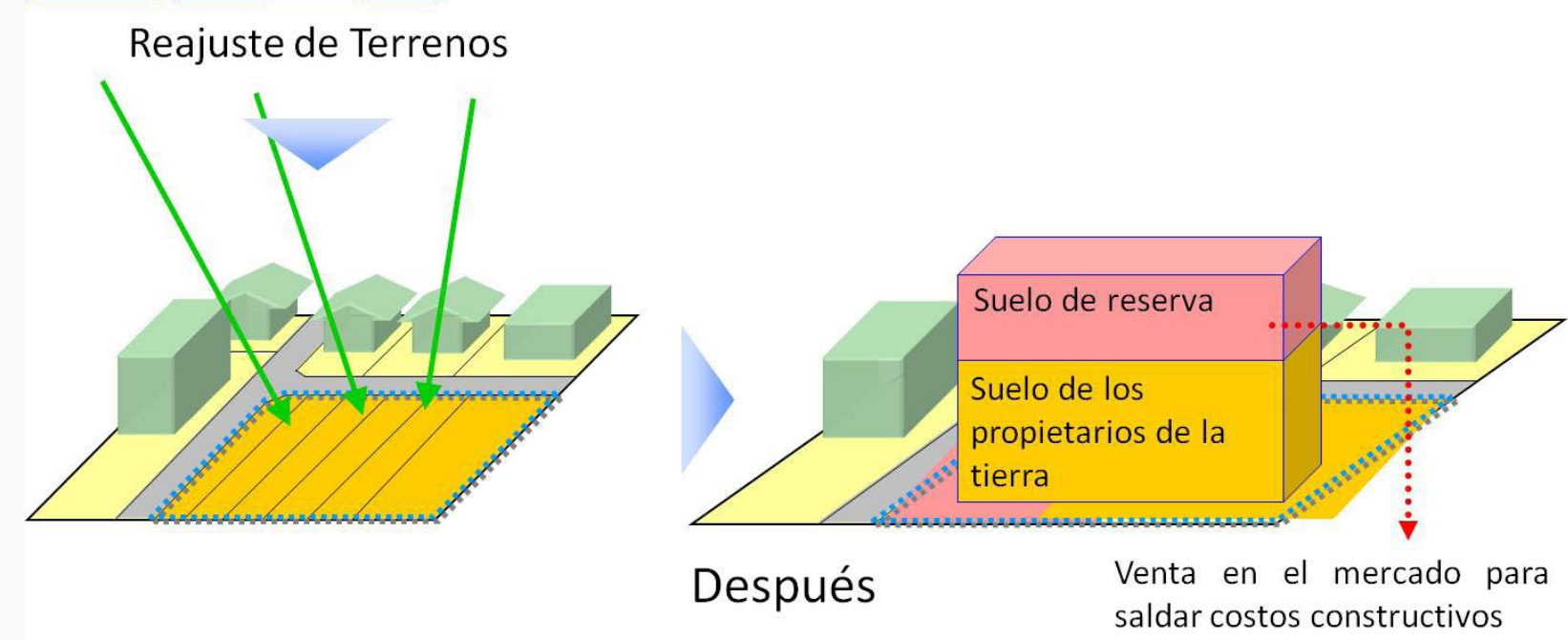

Figura 7. Esquema de reajuste de terrenos, nótese como los propietarios de un sector caracterizado por tener un parcelamiento irregular y ser de interés de renovación, contribuyen con sus terrenos, los cuales luego son retribuidos proporcionalmente. Imagen: Arq. Minoru Matsui.

\footnotetext{
$7 \quad$ Artículo 53, Ley de Planificación Urbana (4240).

8 Básicamente, el reajuste de terrenos se refiere a procesos de integración inmobiliaria, donde los propietarios ceden sus terrenos para dar paso a nuevos proyectos que implican la reconfiguración de un amplio sector urbano. Es una operación fundiaria que pretende revalorizar los predios subutilizados, generando plusvalías que al final son repartidas entre los participantes de la operación. En otras palabras, la cesión que se hace, es una cesión "voluntaria pero interesada" basada en las ganancias que deriven del proyecto final.
} 


\section{Perspectivas de planificación intermedia en Costa Rica}

Carente de un instrumentos que permita la intervención de grandes conjuntos urbanos, es necesario que el país se dé a la tarea de innovar sus herramientas para el desarrollo de proyectos. Esta nueva herramienta debe ser concebida desde un punto de vista de funcionalidad y construcción de ciudad. Al mismo tiempo, debe promover la mejor rentabilidad financiera para los posibles inversionistas. Un proceso de actualización normativa en la línea de la escala intermedia, es necesario para reactivar amplios sectores urbanos y promover la llegada de nuevas inversiones. La fusión de la urbanización y el régimen de propiedad de condominio en un solo proceso de tramitación, puede constituirse en una herramienta interesante de explorar.

Las ciudades costarricenses adolecen de procesos de renovación urbana planificados y sistemáticos. Esta inacción se debe a la miopía sobre la licencia presente en la Ley de Planificación Urbana y a la no exploración de estrategias de reajuste y reparto de cargas y beneficios. Estas estrategias son comunes en la teoría y la práctica urbanística contemporánea. Esto deriva en una limitada cantidad de instrumentos para la planificación de grandes conjuntos, vitales para la consolidación del tejido urbano. Como conclusión adicional, es lógico pensar que, en nuestro contexto normativo, los procesos de reajuste de terrenos impulsados por las municipalidades y el Estado solo son posibles, en el marco de la renovación urbana.

A continuación, se proponen algunos criterios para determinar las áreas que podrían albergar proyectos de escala intermedia, en el contexto de la renovación urbana presente en la normativa costarricense:

1. Áreas estratégicamente ubicadas dentro de la ciudad que hayan perdido funcionalidad o hayan caído en deterioro y cuya ubicación, accesibilidad y dotación de infraestructura permita su uso intensivo y revitalización. Este tipo de planificación intermedia, podría abarcar desde una cuadra ya constituida -incluyendo la integración de sus predios- hasta un conjunto de cuadras que se busque remodelar o renovar. Muchas zonas de San José y otras cabeceras de cantón que se encuentran totalmente servidas de servicios básicos, pero sus infraestructuras abandonas o en estado ruinoso pueden ser una buena posibilidad de exploración. En medio de una trama urbana consolidada, no sería necesario el reajuste vial, pero si la integración predial y el reparto de cargas y beneficios.

2. Áreas con potencial patrimonial que se consideren como posibles conjuntos a ser recuperados e integrados a la dinámica funcional de la ciudad. Incluir el concepto del 
conjunto patrimonial es importante para efectos de conservar la infraestructura de interés, asociarle usos del suelo que promuevan su conservación y disfrute, y renovar las edificaciones circundantes, de manera que se respete el paisaje y se revitalice la vida urbana. Este tipo de planificación intermedia es la base del rescate de grandes centros históricos y culturales en el mundo.

3. Áreas que por su inadecuado parcelamiento impidan un correcto desarrollo del tejido urbano. Este tipo de proyecto es de vital importancia para controlar el crecimiento de la ciudades y terminar de consolidar zonas sub urbanas de las periferias. Estas intervenciones se centran en el reajuste de las geometrías prediales y la definición de los límites urbanos de la ciudad. El plan de escala intermedia, debe establecer claramente el perímetro a ser intervenido y puede estar asociado a la construcción de infraestructura vial importante.

4. Áreas residenciales que precisen de intervenciones de mejoramiento barrial o bien por estar en zonas de riesgo. Al igual que el tema del conjunto patrimonial, en este caso el plan de escala intermedia es un "plan zonal" que determina un conjunto residencial como importante. Por lo tanto, deben señalarse claramente los componentes a conservar y los componentes por renovar.

5. Áreas de asentamientos informales, donde se requiera la erradicación de tugurios, mejoramiento de la infraestructura urbana o bien su formalización. En el caso de la consolidación de asentamientos informales, se deben tener todos los insumos técnicos previos que demuestren las posibilidades reales de consolidación en sitio del asentamiento, incluyendo estudios de riesgo, acceso y capacidad para la dotación de servicios básicos y un análisis costo-beneficio que demuestre la pertinencia de la intervención. Para la intervención de asentamientos informales, el plan de escala intermedia debe considerar la introducción de "normas de excepción" o de "desempeño" que faciliten la concreción de este tipo de proyectos.

La implementación de herramientas de planificación intermedia, requiere no solo de un marco normativo que las valide - tarea en buena parte responsabilidad del INVU, sino también, de la proactividad de los gobiernos locales para hacer realidad los principios establecidos en los diferentes planes reguladores y establecer procesos 
conjuntos con el sector privado. Por otra parte, el sector privado puede ejercer una presión importante con el objetivo de abrir nuevos nichos de inversión en la figura de la construcción -o redefinición- de grandes conjuntos urbanos.

En Costa Rica es preciso emprender un proceso de actualización normativa que incluya instrumentos para la gestión de intervenciones urbanas estratégicas. Estas intervenciones deben considerar los postulados existentes en el capítulo VI de la Ley de Planificación Urbana (4240) referentes a la Renovación Urbana. Como se mencionó anteriormente, una figura hibrida entre la urbanización y el régimen de propiedad en condominio constituye una posibilidad por explorar.

En ese sentido, los proyectos de escala intermedia en nuestro país tienen su cabida en el marco de la renovación urbana establecida en la mencionada ley. Estos proyectos deben obedecer a un programa de renovación urbana, el cual puede ser realizado por las municipalidades o por el Instituto Nacional de Vivienda y Urbanismo?.

Es necesario delimitar el alcance de los condominios horizontales, aclarando -tanto normativamente como en su proceso de tramitación- la diferencia entre los procesos de transformación del suelo necesarios (urbanización o fraccionamientos) y el régimen de propiedad al que son sometidos con posterioridad (condominio). En otras palabras, no existe el condominio como técnica de transformación del suelo exenta de las cargas urbanísticas. Los condominios en esencia son urbanizaciones o fraccionamientos que son sometidos a un régimen de propiedad privada. El reglamento a la Ley de la Propiedad en Condominio debe ser revisado y corregido para evitar esa confusión.

\footnotetext{
$9 \quad$ Ante la ausencia de planes reguladores, el transitorio II de la Ley de Planificación Urbana otorga al Instituto Nacional de Vivienda y Urbanismo (INVU), la competencia residual de generar la normativa urbanística en los territorios sin regulaciones locales: "El Instituto dictará las normas de desarrollo relativas a las materias a que se refiere el artículo 21 de esta Ley. Podrá además, confeccionar los planes reguladores y delimitar los distritos urbanos y demás áreas sujetas a control urbanístico, en tanto las municipalidades no hubieren promulgado en la respectiva materia, o parte de ella, sus propias disposiciones locales con ajuste a esta ley" (Ley 5900 1976). Esta competencia ha sido reiterada en el fallo 4205 de 1996, de la Sala Constitucional.
} 


\section{Referencias}

García Bellido, J. (1998). Perspectivas del nuevo urbanismo colombiana: un análisis de su estructura. Desarrollo Urbano En Cifras Rev. CENAC \& Viceministerio de Vivienda, Desarrollo Urbano Y Agua Potable, Ministerio de Desarrollo Económico, Bogotá Colombia, (5), 118-194.

Jiménez Céspedes, R. A. (2015). Urbanismo e instrumentos de gestión del suelo en Costa Rica. Habitar, (86), 48-53.

Kinoshita, Y. (2013). The international target range of Japan's land readjustment system in technical cooperation. Regional development methodologies and technologies popping out to the world. Regional Development, (585).

Maldonado Copello, M. M. (2006). Planes parciales, gestión asociada y mecanismos de distribución equitativa de cargas y beneficios en el sistema urbanístico colombiano : marco jurídico, conceptos básicos y alternativas de aplicación. Bogotá: Lincoln Institute of Land Policy.

Ministerio das Ciudades. (2010). El Estatuto de la ciudad de Brasil, un comentario. Ministerio das Cidades. Sao Paulo - Brasil.

Pinto Carrillo, Augusto. (2005). La distribución equitativa de cargas y beneficios en Colombia (y algunas referencias sobre la experiencia de Japón). Ciudad y Territorio, XXXVII (143), pp 89-104.

Programa de las Naciones Unidas para los Asentamientos Humanos - ONU HABITAT. (2012). Estado de las ciudades de América Latina y el Caribe 2012. Brasil: UN Habitat.

\section{Legislación consultada}

Asamblea Legislativa, República de Costa Rica. Ley de Planificación Urbana $N^{\circ} 4240$. 1967.

Asamblea Legislativa, República de Costa Rica. Código Municipal, Ley No7794.1998.

Conferencia Europea de Ministros Responsables de la Ordenación del Territorio. (1983). Carta Europea de Ordenamiento Territorial. 10 de enero del 2016, de Consejo de Europa Sitio web: http://www.ehu.eus/Jmoreno/ArchivosPOT/CartaEuropeaOT.Pdf. 
Congreso de Colombia. Ley 388 de ordenamiento territorial. 1997.

Instituto Nacional de Vivienda y Urbanismo. Reglamento para el Control Nacional del Fraccionamientos y Urbanizaciones. 1982.

Instituto Nacional de Vivienda y Urbanismo. Reglamento de Construcciones. 1982

Presidencia de la República de Costa Rica. Reglamento a la Ley de la Propiedad en Condominio. DECRETO No 32303-MIVAH-MEIC-TUR. 2005.

Real Decreto Legislativo 7/2015, de 30 de octubre. Ley del Suelo y Rehabilitación Urbana de España. 2015. 

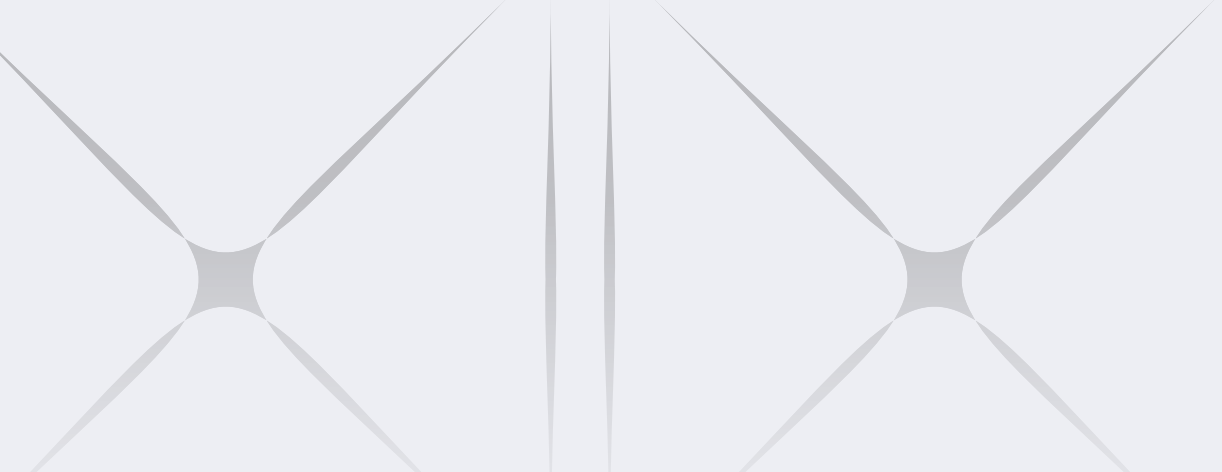

Este artículo forma parte de:

\section{REVISTARQUIS / 10}

Para más información, artículos, e instructivo de publicación, visite:

www.arquis.ucr.ac.cr/revistarquis.html 